\title{
Muscular Fitness Mediates the Association between 25-Hydroxyvitamin D and Areal Bone Mineral Density in Children with Overweight/Obesity
}

\author{
Jose J. Gil-Cosano ${ }^{1, *}$, Luis Gracia-Marco ${ }^{1,2, *}$ (D) , Esther Ubago-Guisado ${ }^{1,3}$, Jairo H. Migueles ${ }^{1}$, \\ Jose Mora-Gonzalez ${ }^{1}$, María V. Escolano-Margarit ${ }^{4}$, José Gómez-Vida ${ }^{4}$, José Maldonado ${ }^{5,6}$ and \\ Francisco B. Ortega ${ }^{1}$ (D) \\ 1 PROFITH “PROmoting FITness and Health through Physical Activity" Research Group, Sport and Health \\ University Research Institute (iMUDS), Department of Physical Education and Sports, Faculty of Sport \\ Sciences, University of Granada, 18071 Granada, Spain; esther.ubago@gmail.com (E.U.-G.); \\ jairohm@ugr.es (J.H.M.); jmorag@ugr.es (J.M.-G.); ortegaf@ugr.es (F.B.O.) \\ 2 Growth, Exercise, Nutrition and Development Research Group, University of Zaragoza, 50009 Zaragoza, \\ Spain \\ 3 Universidad de Castilla-La Mancha, Health and Social Research Center, 16002 Cuenca, Spain \\ 4 Department of Pediatrics, San Cecilio Hospital, 18012 Granada, Spain; \\ mv.escolano@hotmail.com (M.V.E.-M.); gomezvida@gmail.com (J.G.-V.) \\ 5 Department of Pediatrics, School of Medicine, University of Granada, 18016 Granada, Spain; jmaldon@ugr.es \\ 6 The Institute of Biomedicine Research (Instituto de Investigación Biosanitaria (IBS), 18014 Granada, Spain \\ * Correspondence: josejuangil@ugr.es (J.J.G.-C.); lgracia@ugr.es (L.G.-M.); Tel.: +34-958-244-352 (J.J.G.-C.)
}

Received: 30 September 2019; Accepted: 11 November 2019; Published: 14 November 2019

\begin{abstract}
The association between vitamin $\mathrm{D}[25(\mathrm{OH}) \mathrm{D}]$ and bone health has been widely studied in children. Given that $25(\mathrm{OH}) \mathrm{D}$ and bone health are associated with muscular fitness, this could be the cornerstone to understand this relationship. Hence, the purpose of this work was to examine if the relation between $25(\mathrm{OH}) \mathrm{D}$ and areal bone mineral density (aBMD) was mediated by muscular fitness in children with overweight/obesity. Eighty-one children (8-11 years, 53 boys) with overweight/obesity were included. Body composition was measured with dual energy X-ray Absorptiometry (DXA), $25(\mathrm{OH}) \mathrm{D}$ was measured in plasma samples and muscular fitness was assessed by handgrip and standing long jump tests (averaged z-scores were used to represent overall muscular fitness). Simple mediation analyses controlling for sex, years from peak height velocity, lean mass and season were carried out. Our results showed that muscular fitness z-score, handgrip strength and standing long jump acted as mediators in the relationship between $25(\mathrm{OH}) \mathrm{D}$ and aBMD outcomes (percentages of mediation ranged from $49.6 \%$ to $68.3 \%$ ). In conclusion, muscular fitness mediates the association of $25(\mathrm{OH}) \mathrm{D}$ with aBMD in children with overweight/obesity. Therefore, $25(\mathrm{OH}) \mathrm{D}$ benefits to bone health could be dependent on muscular fitness in young ages.
\end{abstract}

Keywords: Vitamin D; strength; bone health; mediation; childhood; obesity

\section{Introduction}

The World Health Organization defines osteoporosis as a systemic skeletal disease characterized by low bone density and microarchitectural deterioration of bone tissue [1]. Acquiring an optimal bone mineral accrual during childhood (i.e., late childhood and peripubertal years) is considered an important factor for reducing the risk of osteoporosis later in life [2]. In general, children with overweight/obesity usually have a greater areal bone mineral density (aBMD) than normal-weight children as they mature earlier, tend to be taller and have greater lean mass [2]. Notwithstanding, 
Rokoff et al. [3] recently showed central adiposity to be inversely associated with aBMD Z-score at the total body less head (TBLH) in children with high levels of abdominal fat.

Childhood obesity is associated with a deficient 25(OH)D status in Spain [4]. Vitamin D status is reflected by 25 -hydroxyvitamin $\mathrm{D}(25(\mathrm{OH}) \mathrm{D})$ levels and its concentration in children with obesity is influenced by vitamin $\mathrm{D}$ intake, season, ethnicity/race, decreased exposure to sunlight as a consequence of the sedentary lifestyle, or by $25(\mathrm{OH}) \mathrm{D}$ sequestration through adipose tissue [5]. This prohormone is essential for bone development and remodeling processes, as well as for normal calcium and phosphorus homeostasis [6]. Some studies evidenced that 25(OH)D-deficient children had lower aBMD Z-score at the lumbar spine (LS) and the total body, probably influenced by the consequent increase in parathormone levels $[7,8]$.

Moderate-to-high muscular fitness at a young age is a powerful determinant of health [9]. In this regard, Torres-Costoso et al. [10] found that children with good performance in handgrip and standing long jump had better and worse bone health, respectively. The latter associations were fully mediated by lean mass, whose function seems to be influenced by 25(OH)D levels [11]. When calcitriol $\left(1,25(\mathrm{OH})_{2} \mathrm{D}\right.$, an active metabolite of vitamin $\left.\mathrm{D}\right)$ activates the nuclear vitamin D receptor (VDR), several slow pathways are activated leading to cytoskeletal protein synthesis important for muscle function (i.e., calmodulin, calbindin D-9K or insulin-like growth factor binding protein-3) [12-14]. Moreover, the activation of the nuclear VDR also increases phosphate metabolism via increases in the uptake and accumulation of phosphate and ATP, resulting in positive effects on muscle contraction [15]. In addition, the $1,25(\mathrm{OH})_{2} \mathrm{D}$ activation of the membranous VDR stimulates rapid actions that affect $\mathrm{Ca}^{2+}$ handling and muscle cell proliferation and differentiation [16].

Although the relationship between 25(OH)D and muscular fitness has been described in youth, no study has jointly examined the association of these predictors with aBMD outcomes. Most published studies have been conducted using statistical multivariate procedures in order to control for potential confounders, but these statistical procedures are unable to distinguish between confounding and mediating variables. Mediation analysis allows us to clarify the process underlying the relationship between two variables and the extent to which this relationship can be modified or confounded by a third variable [17]. Therefore, the aim of this study was to examine whether the relationship between $25(\mathrm{OH}) \mathrm{D}$ and aBMD outcomes is mediated by muscular fitness in children with overweight/obesity.

\section{Materials and Methods}

\subsection{Design}

A cross-sectional analysis was conducted of the baseline measurements of the ActiveBrains project (registered at Clinicaltrials.gov, number NCT02295072). A detailed description of the study has been published elsewhere [18]. The ActiveBrains project measured 110 children with overweight/obesity aged 8-11 years from Granada (south of Spain) according to the following inclusion criteria: (1) to be overweight or obese based on the World Obesity Federation (formerly named International Obesity Task Force) cut-off points (2) to be 8 to 11 years old, (3) not to have any physical disabilities or neurological disorder that affects their physical performance, and (4) in the case of girls, not to have started the menstruation at the moment of the assessments.

A total of 81 children with overweight/obesity (10.0 \pm 1.2 years old, $65 \%$ boys) with valid data on $25(\mathrm{OH}) \mathrm{D}$, muscular fitness variables, body composition (i.e., bone, fat and lean mass) and sexual maturation were included in this report. Participants were recruited from the Pediatric Unit of the "San Cecilio" and "Virgen de las Nieves" University Hospitals in the province of Granada, Spain. Furthermore, we contacted several schools of Granada and we advertised the study in the local media, inviting any child meeting the inclusion criteria. The study protocol was approved by the Ethics Committee on Human Research (CEIH) of the University of Granada (Reference: 848, February 2014). Written consent was obtained from parents for the participation of their children. 


\subsection{Measures}

\subsubsection{Anthropometrics and Sexual Maturation}

Participants were weighed using an electronic scale (SECA 861, Hamburg, Germany) with an accuracy of $100 \mathrm{~g}$. A precision stadiometer was used to assess height $(\mathrm{cm})$ and sitting height (SECA 225 , Hamburg, Germany) to the nearest $0.1 \mathrm{~cm}$. BMI was calculated as body mass $(\mathrm{kg}) / \mathrm{height}\left(\mathrm{m}^{2}\right)$ and the participants were classified as overweight or obese according to sex- and age-specific BMI cut-offs defined by Cole et al. [19].

Somatic maturity offset was assessed as years from peak height velocity (PHV) from age, height and sitting height using validated algorithms for children [20]. In boys: $-8.128741+(0.0070346 \times$ (age $\times$ sitting height)), where $R^{2}=0.906$ and the standard error of the estimate $=0.514$. In girls: $-7.709133+$ $(0.0042232 \times($ age $\times$ height $))$, where $R^{2}=0.898$ and the standard error of the estimate $=0.528$. PHV is the period of time of maximum growth in stature and therefore, years from PHV are considered in terms of time before and time after the PHV.

\subsubsection{Vitamin D}

Venous blood samples were obtained between 8:00 a.m. and 9:00 a.m. by venipuncture after an overnight fast (at least 12 h) from September 2015 to February 2016 (Autumn and Winter). Blood samples in tubes containing EDTA were spun immediately at 30,000 g for $10 \mathrm{~min}$. Plasma was isolated and stored at $-80^{\circ} \mathrm{C}$ until assayed. Plasma $25(\mathrm{OH}) \mathrm{D}$ was analyzed by immunoturbidimetry (Alinity i 25-OH Vitamin D Reagent Kit ref. 08P4522, Abbot, IL, USA) with a sensitivity of $3.5 \mathrm{ng} / \mathrm{mL}$ and an intra-assay coefficient of variation of $2.5 \%$.

\subsubsection{Muscular Fitness}

Upper-body muscular fitness was assessed using the handgrip strength test through a dynamometer with an adjustable grip (TKK 5101 Grip D, Takey, Tokyo Japan). Participants were instructed to squeeze continuously for $\geq 2 \mathrm{~s}$ with the elbow in full extension position. The test was repeated twice (right and left hands alternately). The best score of the 2 attempts for each hand was chosen and averaged [21]. Finally, relative upper-body muscular fitness was expressed per kg of body mass (Handgrip strength $(\mathrm{kg} / \mathrm{kg})$ ). Lower-body muscular fitness was assessed by the standing long jump test. Participants were instructed to push off vigorously and jump as far forward as possible, trying to land on both feet. The distance reached was taken in centimeters from the take-off line and the heel of the nearest foot at landing. The longest attempt from 3 was recorded $(\mathrm{cm})$. The scientific rationale for the selection of these tests, as well as their validity and reliability, has previously been demonstrated in children and adolescents [21].

A muscular fitness score (muscular fitness $z$-score) was computed by combining the standardized values of handgrip strength $(\mathrm{kg} / \mathrm{kg})$ and standing long jump $(\mathrm{cm})$. Each of these variables was standardized as follows: $z$-score $=(i$ th value - mean $) / \mathrm{SD}$. The muscular fitness $z$-score was calculated as the mean of the 2 standardized scores (handgrip strength and standing long jump).

\subsubsection{Body Composition}

Children were scanned with dual-energy X-ray Absorptiometry (DXA) using the Hologic Discovery Wi (Hologic Series Discovery QDR, Bedford, MA, USA). The DXA equipment was calibrated at the start of each testing day by using a lumbar spine phantom as recommended by the manufacturer. All DXA scans and analyses were performed using the GE encore software (version 4.0.2) following the same protocol by the same researcher. The positioning of the participants and the analyses of the results were undertaken following recommendations from the International Society of Clinical Densitometry [22]. The total body scan was used to obtain fat mass, lean mass, and aBMD at the TBLH, arms, and legs. 


\subsection{Statistical Analysis}

Descriptive characteristics of the participants are presented as mean \pm standard deviation (SD) or percentages. All variables were checked for normality using visual check of histograms, Q-Q and box plots. Interaction analyses were performed for sex and since no significant interactions were found $(p \leq 0.28)$, analyses were performed for boys and girls together.

A partial correlation analysis controlling for sex and years from PHV was performed to examine the relationship between $25(\mathrm{OH}) \mathrm{D}$, muscular fitness variables, TBLH lean mass, and TBLH fat mass.

We carried out a mediation analysis controlling for sex, years from PHV, TBLH lean mass and season to test whether the association between 25(OH)D and aBMD outcomes was mediated by muscular fitness. These covariates were selected because of their well-known association with aBMD [23,24]. The PROCESS macro version 3.1, model 4, with 10,000 bias-corrected bootstrap samples and $95 \%$ confidence intervals was used for these analyses. In a nutshell, the mediation analysis is composed of ordinary least squared regression-based equations (paths) that allow us to answer the question of how a predictor transmits its effect (total effect) on an outcome being partitioned into direct ( $\mathrm{c}^{\prime}$ path) and indirect effect $(\mathrm{a} \times \mathrm{b}$ path). Most contemporary analysts focus on the indirect effect by stating 2 steps in establishing mediation [25]: (1) show that the causal variable is correlated with the mediator (path a); (2) show that the mediator affects the outcome variable controlling for the predictor (path b). Thus, mediation is assessed by the indirect effect of the $25(\mathrm{OH}) \mathrm{D}$ (predictor) on aBMD (outcome) through muscular fitness (mediator). The total (c path), direct ( $c^{\prime}$ path), and indirect effects $(\mathrm{a} \times \mathrm{b}$ paths) are presented (Figure 1). Indirect effects with confidence intervals not including zero were interpreted as statistically significant [25] regardless of the significance of the total effect (the effect of 25(OH)D on aBMD outcomes) and the direct effect (the effect on aBMD outcomes when both $25(\mathrm{OH}) \mathrm{D}$ and muscular fitness are included as independent variables). The percentage of mediation $\left(\mathrm{P}_{\mathrm{M}}\right)$ was calculated as "(indirect effect/total effect) $\times 100$ " to know how much of the total effect was explained by the mediation when the following assumptions were achieved: the total effect is larger than the indirect effect and of the same sign. All the analyses were performed using the IBM SPSS Statistics for Windows version 20.0 (IBM Corp: Armonk, NY, USA), and the level of significance was set to $p<0.05$.
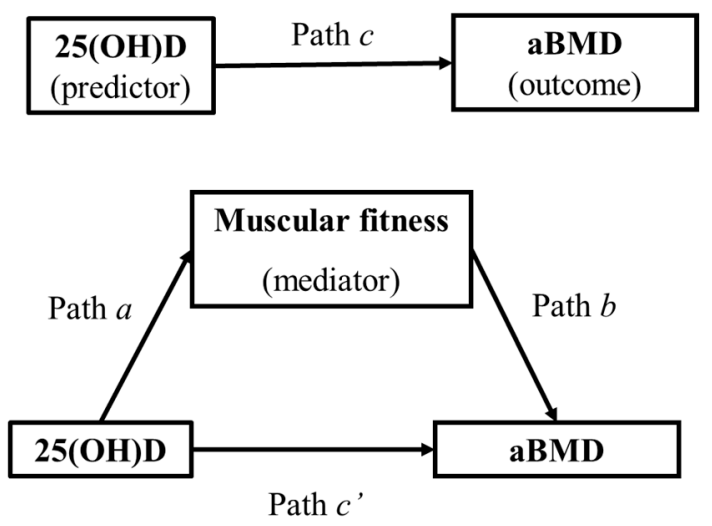

Figure 1. Causal diagram reflecting the simple mediation analyses. Path c shows the association between the predictor and the outcome. Arrows a $\times$ b show the natural indirect effect pathway, and $c^{\prime}$ shows the natural direct effect pathway. $a B M D$ : areal bone mineral density.

\section{Results}

Table 1 shows the raw descriptive characteristics of the participants at baseline (mean \pm SD). Briefly, the mean age of the participants was $10.0 \pm 1.2$ years and they were $2.4 \pm 0.9$ years below PHV, overweight and obesity was evident in $28.4 \%$ and $71.6 \%$ of them, respectively; the mean $25(\mathrm{OH}) \mathrm{D}$ concentration was $31.5 \mathrm{nmol} / \mathrm{L}$ and only $6.2 \%$ of the children measured fell above the suggested cut-off of $50 \mathrm{nmol} / \mathrm{L}$ [26]. 
Table 1. Characteristics of the study sample by sex.

\begin{tabular}{|c|c|c|c|}
\hline Variables & All $(n=81)$ & Boys $(n=53)$ & Girls $(n=28)$ \\
\hline Age (years) & $10.0 \pm 1.2$ & $10.2 \pm 1.2$ & $9.7 \pm 1.2$ \\
\hline Years from PHV (years) & $-2.4 \pm 0.9$ & $-2.6 \pm 0.9$ & $-1.8 \pm 1.1$ \\
\hline Height $(\mathrm{cm})$ & $143.9 \pm 8.7$ & $144.5 \pm 8.1$ & $142.7 \pm 9.8$ \\
\hline Body mass (kg) & $54.8 \pm 10.7$ & $55.8 \pm 10.7$ & $53.1 \pm 10.8$ \\
\hline TBLH fat mass $(\mathrm{kg})^{\text {a }}$ & $21.9 \pm 5.8$ & $22.1 \pm 5.9$ & $21.5 \pm 5.8$ \\
\hline TBLH lean mass $(\mathrm{kg})^{\text {a }}$ & $26.6 \pm 5.2$ & $27.3 \pm 4.9$ & $25.5 \pm 5.3$ \\
\hline $\mathrm{BMI}\left(\mathrm{kg} \cdot \mathrm{m}^{-2}\right)$ & $26.3 \pm 3.4$ & $26.5 \pm 3.4$ & $25.9 \pm 3.3$ \\
\hline Overweight (\%) & 28.4 & 26.4 & 32.1 \\
\hline Obesity $(\%)$ & 71.6 & 73.6 & 67.9 \\
\hline Autumn (\%) & 91.4 & 90.6 & 92.9 \\
\hline Winter $(\%)$ & 8.6 & 9.4 & 7.1 \\
\hline $25(\mathrm{OH}) \mathrm{D}(\mathrm{nmol} / \mathrm{L})^{\mathrm{a}, *}$ & $31.5 \pm 9.5$ & $32.7 \pm 9.6$ & $29.2 \pm 8.9$ \\
\hline Deficiency $(\%)$ & 46.9 & 43.4 & 53.6 \\
\hline Insufficiency (\%) & 46.9 & 49.1 & 42.9 \\
\hline Sufficiency $(\%)$ & 6.2 & 7.5 & 3.6 \\
\hline Muscular fitness $z$-score ${ }^{\mathrm{b}}$ & $0.000 \pm 1.000$ & $0.032 \pm 0.098$ & $-0.061 \pm 1.037$ \\
\hline Handgrip strength $(\mathrm{kg}) /$ body mass $(\mathrm{kg})^{a}$ & $0.307 \pm 0.059$ & $0.309 \pm 0.058$ & $0.303 \pm 0.059$ \\
\hline Standing long jump $(\mathrm{cm})^{a}$ & $106.2 \pm 17.8$ & $106.5 \pm 17.9$ & $105.7 \pm 17.9$ \\
\hline TBLH $\left(\mathrm{g} \cdot \mathrm{m}^{-2}\right)^{\mathrm{a}}$ & $0.772 \pm 0.059$ & $0.775 \pm 0.059$ & $0.766 \pm 0.058$ \\
\hline $\operatorname{Arms}\left(\mathrm{g} \cdot \mathrm{m}^{-2}\right)^{\mathrm{a}}$ & $0.607 \pm 0.041$ & $0.613 \pm 0.041$ & $0.596 \pm 0.040$ \\
\hline Legs $\left(g \cdot \mathrm{m}^{-2}\right)^{a}$ & $0.913 \pm 0.079$ & $0.917 \pm 0.082$ & $0.906 \pm 0.074$ \\
\hline
\end{tabular}

PHV peak height velocity; TBLH total body less head; BMI body mass index; 25(OH)D 25-hydroxyvitamin D; aBMD areal bone mineral density; ${ }^{\text {a }}$ Values were Blom-transformed before analysis, but non-transformed values are presented; ${ }^{b} Z$-score mean computed from handgrip strength $(\mathrm{kg} / \mathrm{kg})$ and standing long jump $(\mathrm{cm})$ tests; *Vitamin D status was defined as follows [26]: Sufficiency, $>50 \mathrm{nmol} \cdot \mathrm{L}^{-1}$; Insufficiency, $30-50 \mathrm{nmol} / \mathrm{L}^{-1}$; Deficiency, $<30 \mathrm{nmol} / \mathrm{L}^{-1}$.

Partial correlations between $25(\mathrm{OH}) \mathrm{D}$, muscular fitness variables, TBLH fat mass and TBLH lean mass after adjustment for sex and years from PHV are presented in Table 2. 25(OH)D was positively correlated with muscular fitness $z$-score and handgrip strength ( $r=0.28$ and $r=0.29$, respectively). Muscular fitness $z$-score was positively correlated with TBLH aBMD and arms aBMD $(r=0.24$ and $\mathrm{r}=0.35$, respectively), whilst handgrip strength was positively correlated with arms aBMD $(r=0.32)$. Finally, standing long jump was positively correlated with aBMD at TBLH, arms and legs $(r=0.27$, $r=0.29$ and $r=0.23$, respectively).

Table 2. Partial coefficients of the independent variable with muscular fitness variables and aBMD outcomes adjusted for sex and years from PHV.

\begin{tabular}{|c|c|c|c|c|c|c|}
\hline & $\begin{array}{l}\text { Muscular } \\
\text { Fitness } \\
z \text {-Score }\end{array}$ & $\begin{array}{l}\text { Handgrip } \\
\text { Strength/Body } \\
\text { Mass }\end{array}$ & $\begin{array}{l}\text { Standing } \\
\text { Long Jump }\end{array}$ & $\begin{array}{l}\text { TBLH } \\
\text { aBMD }\end{array}$ & $\begin{array}{l}\text { Arms } \\
\text { aBMD }\end{array}$ & $\begin{array}{l}\text { Legs } \\
\text { aBMD }\end{array}$ \\
\hline $25(\mathrm{OH}) \mathrm{D}$ & 0.275 * & $0.285 *$ & 0.186 & 0.039 & 0.043 & -0.011 \\
\hline Muscular fitness z-score ${ }^{b}$ & - & $0.881 * *$ & $0.869 * *$ & $0.244 *$ & $0.352 *$ & 0.182 \\
\hline Handgrip strength/body mass & & - & $0.540 * *$ & 0.165 & $0.320 *$ & 0.089 \\
\hline Standing long jump & & & - & $0.266 *$ & $0.295 *$ & $0.233 *$ \\
\hline TBLH aBMD & & & & - & $0.764 * *$ & $0.894 * *$ \\
\hline Arms aBMD & & & & & - & $0.577 * *$ \\
\hline
\end{tabular}

PHV peak height velocity; $25(\mathrm{OH}) D$ 25-hydroxyvitamin D; TBLH total body less head: $a B M D$ areal bone mineral density; ${ }^{b} Z$-score mean computed from handgrip strength $(\mathrm{kg} / \mathrm{kg})$ and standing long jump $(\mathrm{cm})$ tests; Boldface indicates statistical significance: ${ }^{*} p<0.050,{ }^{* *} p<0.001$. 


\section{Mediation Analysis}

Mediation analysis models are depicted in Figure 2. 25(OH)D was not significantly associated with any of the aBMD outcomes (c, total effect). Regarding path a, $25(\mathrm{OH}) \mathrm{D}$ was positively associated with muscular fitness $z$-score (Figure 2A, $\beta=0.277, p=0.023$ ) and handgrip strength (Figure $2 B, \beta=0.252$, $p=0.038$ ). In the path $b$, in all mediation models, muscular fitness was positively associated with TBLH aBMD (Figure 2A, $\beta=0.210, p=0.004$ ), arms aBMD (Figure $2 B, \beta=0.319, p<0.001$ ) and legs aBMD (Figure $2 \mathrm{C}, \beta=0.204, p=0.007$ ). Finally, when $25(\mathrm{OH}) \mathrm{D}$ and muscular fitness were simultaneously included as independent variables ( $c^{\prime}$, direct effect), aBMD outcomes were not predicted. There was a significant mediating effect of muscular fitness on the relationship of 25(OH)D with TBLH aBMD, arms aBMD and legs aBMD ( $\mathrm{P}_{\mathrm{M}}$ ranged from 49.6 to $\left.68.3 \%\right)$.

A

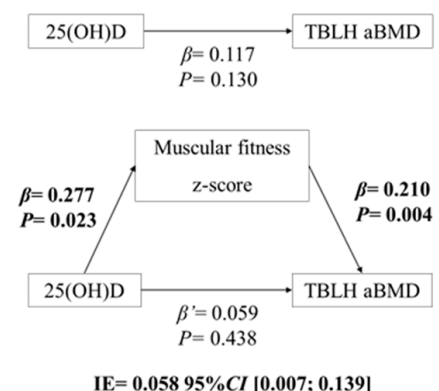

$\mathrm{IE}=0.05895 \% C I[0.007 ; 0.139]$ $\%$ Med: $49.6 \%$

B
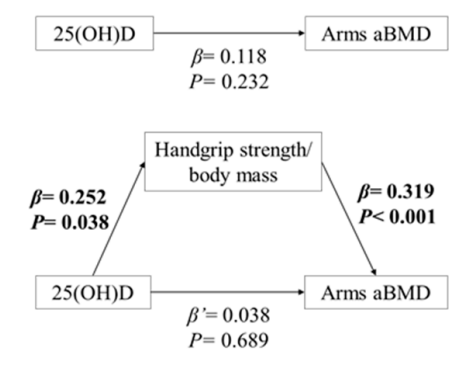

$\mathrm{IE}=0.08095 \% C I[0.001 ; 0.191]$

\% Med: $67.8 \%$

C
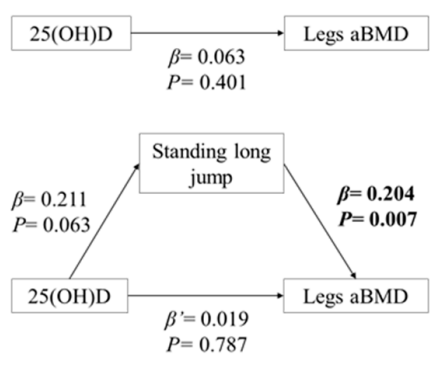

$\mathrm{IE}=0.04395 \% C I[0.001 ; 0.110]$

$\%$ Med: $68.3 \%$

Figure 2. Simple mediation models of the relationship between $25(\mathrm{OH}) \mathrm{D}$ and aBMD outcomes using muscular fitness as a mediator, controlling for sex, years from PHV, TBLH lean mass and season. Muscular fitness $z$-score was used as a mediator in panel (A), handgrip strength/body mass was used as mediator in panel (B) and standing long jump was used as a mediator in panel (C). Z-score mean computed from handgrip strength $(\mathrm{kg} / \mathrm{kg})$ and standing long jump $(\mathrm{cm})$ tests; $P H V$ peak height velocity; TBLH total body less head; 25(OH)D 25-hydroxyvitamin D; $a B M D$ areal bone mineral density 


\section{Discussion}

In the present study, we revealed a mediating effect of muscular fitness on the relationship between 25(OH)D levels and aBMD at the TBLH, arms, and legs after controlling for sex, years from PHV, TBLH lean mass and season. To the best of our knowledge, this is the first study in children with overweight/obesity analyzing whether muscular fitness acts as mediator in the association between 25(OH)D and aBMD outcomes.

Our results show no significant association between 25(OH)D and aBMD outcomes after adjusting for sex, years from PHV, TBLH lean mass and season (path c, total effect). This finding agrees with Hauksson et al. [27] who found no significant association between 25(OH)D levels and bone mineral accrual in Icelandic children at ages 7 and 9. On the contrary, Pekkinen et al. [7] reported that 25(OH)D status was a key determinant of aBMD in children and adolescents. In this regard, 25(OH)D status has been highlighted as a significant predictor of peak bone mass in males but not in females during childhood [28]. Likewise, non-significant associations between $25(\mathrm{OH}) \mathrm{D}$ and bone outcomes have been reported in American prepubertal girls after adjusting for potential cofounders [29] and in Finnish prepubertal girls after adjustment for maturation and BMI [8]. This could be explained by the differences in sex hormone effects on bone since estrogens may counteract the effects of lower 25(OH)D levels in females, whereas in males this compensatory effect is absent [28]. Nevertheless, we did not find sex interaction between $25(\mathrm{OH}) \mathrm{D}$ and aBMD outcomes, suggesting that these sex differences in hormonal effects on bone might not occur in prepubertal children with overweight/obesity since estradiol levels may be high in both boys and girls [30,31].

A few studies have assessed the effect of $25(\mathrm{OH}) \mathrm{D}$ in relation to muscular fitness in children [32-34]. In addition, the present study does so, taking into account different ways of measuring muscular fitness in the upper and lower limbs. The results of the present investigation confirm a relationship between $25(\mathrm{OH}) \mathrm{D}$ levels and muscular fitness $z$-score, handgrip strength and standing long jump (path a). These results agree with Foo et al. [32] who observed that adolescent girls with sufficient 25(OH)D status performed significantly better in handgrip strength compared with those with deficient or severely deficient status. Moreover, our results partly concur with Ward et al. [33] who found a positive association between $25(\mathrm{OH}) \mathrm{D}$ levels and the performance in countermovement jump in British adolescent girls. Otherwise, a study carried out with children did not find any relationship between handgrip strength and 25(OH)D status [34].

In this study, muscular fitness $z$-score, handgrip strength, and standing long jump were positively associated with TBLH aBMD, arms aBMD and legs aBMD, respectively (path b). Torres-Costoso et al. [10] reported a positive association between handgrip strength and aBMD outcomes in children aged 8-11 years, although a negative association between standing long jump and aBMD outcomes was found. The latter inverse association contrasts with our results. A possible explanation for these differences could be the different weight status of the participants included in both studies (BMI, $18.8 \pm 3.8$ vs. $26.3 \pm 3.4$ ). In addition, the fact that our results were adjusted for TBLH lean mass (but not in Torres-Costoso's study) could modify the direction of the association. Our findings agree with the literature and support the fact that bones adapt their resistance to the mechanical stimuli (i.e., body mass and muscle contractions) placed on them [35]. Moreover, it should be noted that the performance in the standing long jump test may be affected by the coordination skills [9], which might not be fully developed in 8-11-year-old children.

Our results show that the total effect of $25(\mathrm{OH}) \mathrm{D}$ on aBMD outcomes was mediated by muscular fitness $z$-score, handgrip strength and standing long jump ( $\mathrm{P}_{\mathrm{M}}$ ranged from 49.6 to $68.3 \%$ ). Since the mediation analysis assumes that the predictor variable causes the mediator [17], muscular fitness may be an intermediate step in the causal pathway of $25(\mathrm{OH}) \mathrm{D}$ with aBMD. There is consistent evidence regarding the bivariate association of muscular fitness with both 25(OH)D [36] and aBMD outcomes [37,38]. Otherwise, the relationship between $25(\mathrm{OH}) \mathrm{D}$ and bone in children remains controversial [27,32]. In addition, a recent study has reported that the association between muscular fitness and aBMD is fully mediated by lean mass, whose function appears to be affected by $25(\mathrm{OH}) \mathrm{D}$ 
levels [11]. Together with our results, this evidence indicates that increasing 25(OH)D levels may increase muscular fitness and, ultimately, the aBMD. As an optimal bone mineral accrual is critical during childhood in order to prevent osteoporosis later in life [2], public health policies should start at an early age. Therefore, school-based interventions aiming at improving outdoor physical activity levels are justified among children to synthesize $25(\mathrm{OH}) \mathrm{D}$ and, ultimately, improve muscular fitness.

\section{Strengths and Limitations}

The current study has several limitations that should be acknowledged. First, our cross-sectional design rules out the possibility of identifying cause-effect relationships. Thus, the reported findings need to be confirmed prospectively. Second, the number of participants with complete data in all studied variables is relatively small. Third, although we did not find interaction by sex, our results need to be confirmed by studying boys and girls separately. Finally, calcium intake was not available and therefore, we did not include it in the model as a cofounder (i.e., vitamin D interacts with calcium affecting bone health [6]).

The present study has also several strengths, such as the use of relevant sets of cofounders (i.e., sex, years from PHV, TBLH lean mass and season) that are crucial to analyze the association of $25(\mathrm{OH}) \mathrm{D}$ with bone outcomes in children. Furthermore, valid and reliable tests for assessing muscular fitness were chosen from the ALPHA-Fitness battery [21]. Finally, we used DXA for assessing aBMD bone outcomes which are the gold standard for measuring bone outcomes and have been used worldwide in the pediatric population [22].

\section{Conclusions}

Muscular fitness plays a key role in the relationship between 25(OH)D levels and aBMD at the TBLH and arms. Increasing 25(OH)D levels may improve muscular fitness and, ultimately, aBMD in children with overweight/obesity. Future longitudinal studies must be conducted in order to confirm these findings.

Author Contributions: J.J.G.-C. was involved in the data collection and conceived the hypothesis, analyzing and drafting the manuscript. J.H.M., J.M.-G., M.V.E.-M., J.G.-V., J.M., and F.B.O. were involved in the study design, data collection, and critical revision. L.G.-M., E.U.-G. and F.B.O. participated in the interpretation of the results and critical revision. All authors have read and approved the final version of the submitted manuscript.

Funding: This study was supported by the Spanish Ministry of Economy and Competitiveness (Reference DEP2013-47540). This study takes place thanks to the additional funding from the University of Granada, UGR Research and Knowledge Transfer Fund (PPIT) 2016, Excellence actions: Units of Scientific Excellence; Scientific Unit of Excellence on Exercise and Health (UCEES) and the European Regional Development Funds (ERDF, ref. SOMM17/6107/UGR). In addition, this study was further supported by the SAMID III network, RETICS, funded by the PN I+D+I 2017-2021 (Spain), ISCIII-Sub-Directorate General for Research Assessment and Promotion and the European Regional Development Fund (ERDF) (Ref. RD16/0022). L.G-M is supported by a fellowship from "la Caixa" Foundation (ID 100010434) and the fellowship code is LCF/BQ/PR19/11700007. J.H.M. and J.M.-G. are supported by the Spanish Ministry of Education, Culture and Sport (FPU15/02645 and FPU14/06837, respectively).

Acknowledgments: The author gratefully acknowledge the children, parents, coaches, hospitals and schools who helped and participated in this study. We are grateful to Ana Yara Postigo Fuentes for her assistance with the English language.

Conflicts of Interest: The authors declare that they have no conflict of interest.

\section{References}

1. World Health Organization. Who Scientific Group on the Assessment of Osteoporosis At Primary Health. World Health 2007. Available online: https://www.who.int/chp/topics/Osteoporosis.pdf (accessed on 3 April 2019).

2. Kelley, J.C.; Crabtree, N.; Zemel, B.S. Bone Density in the Obese Child: Clinical Considerations and Diagnostic Challenges. Calcif. Tissue Int. 2017, 100, 514-527. [CrossRef] [PubMed]

3. Rokoff, L.B.; Rifas-Shiman, S.L.; Switkowski, K.M.; Young, J.G.; Rosen, C.J.; Oken, E.; Fleisch, A.F. Body composition and bone mineral density in childhood. Bone 2019, 121, 9-15. [CrossRef] 
4. Durá-Travé, T.; Gallinas-Victoriano, F.; Chueca-Guindulain, M.J.; Berrade-Zubiri, S. Prevalence of hypovitaminosis D and associated factors in obese Spanish children. Nutr. Diabetes 2017, 7, e248.

5. Alemzadeh, R.; Kichler, J.; Babar, G.; Calhoun, M. Hypovitaminosis D in obese children and adolescents: Relationship with adiposity, insulin sensitivity, ethnicity, and season. Metabolism 2008, 57, 183-191. [CrossRef] [PubMed]

6. Gil, Á.; Plaza-Diaz, J.; Mesa, M.D. Vitamin D: Classic and Novel Actions. Ann. Nutr. Metab. 2018, 72, 87-95. [CrossRef]

7. Pekkinen, M.; Viljakainen, H.; Saarnio, E.; Lamberg-Allardt, C.; Mäkitie, O. Vitamin D is a major determinant of bone mineral density at school age. PLoS ONE 2012, 7, e40090. [CrossRef]

8. Cheng, S.; Tylavsky, F.; Kröger, H.; Kärkkäinen, M.; Lyytikainen, A.; Koistinen, A.; Mahonen, A.; Alen, M.; Halleen, J.; Väänänen, K.; et al. Association of low 25-hydroxyvitamin D concentrations with elevated parathyroid hormone concentrations and low cortical bone density in early pubertal and prepubertal Finnish girls. Am. J. Clin. Nutr. 2003, 78, 485-492. [CrossRef]

9. Ortega, F.B.; Ruiz, J.R.; Castillo, M.J.; Sjöström, M. Physical fitness in childhood and adolescence: A powerful marker of health. Int. J. Obes. 2008, 32, 1-11. [CrossRef]

10. Torres-Costoso, A.; Gracia-Marco, L.; Sánchez-López, M.; García-Prieto, J.C.; García-Hermoso, A.; Díez-Fernández, A.; Martínez-Vizcaíno, V. Lean mass as a total mediator of the influence of muscular fitness on bone health in schoolchildren: A mediation analysis. J. Sports Sci. 2015, 33, 817-830. [CrossRef]

11. Hazell, T.J.; Deguire, J.R.; Weiler, H.A. Vitamin D: An overview of its role in skeletal muscle physiology in children and adolescents. Nutr. Rev. 2012, 70, 520-533. [CrossRef] [PubMed]

12. Brunner, A.; de Boland, A.R. 1,25-Dihydroxyvitamin D3 Affects the Synthesis, Phosphorylation and in vitro Calmodulin Binding of Myoblast Cytoskeletal Proteins. Zeitschrift für Naturforschung C 2018, 45, 1156-1160. [CrossRef] [PubMed]

13. Zanello, S.B.; Boland, R.L.; Norman, A.W. cDNA sequence identity of a vitamin D-dependent calcium-binding protein in the chick to calbindin D-9K. Endocrinology 1995, 136, 2784-2787. [CrossRef] [PubMed]

14. Barton-Davis, E.R.; Shoturma, D.I.; Musaro, A.; Rosenthal, N.; Sweeney, H.L. Viral mediated expression of insulin-like growth factor I blocks the aging-related loss of skeletal muscle function. Proc. Natl. Acad. Sci. USA 1998, 95, 15603-15607. [CrossRef] [PubMed]

15. Boland, R.; de Boland, A.R.; Marinissen, M.J.; Santillan, G.; Vazquez, G.; Zanello, S. Avian muscle cells as targets for the secosteroid hormone 1,25-dihydroxy-vitamin D3. Mol. Cell. Endocrinol. 1995, 114, 1-8. [CrossRef]

16. De Boland, A.R.; Nemere, I. Rapid actions of vitamin D compounds. J. Cell. Biochem. 1992, 49, 32-36. [CrossRef]

17. Baron, R.M.; Kenny, D.A. The moderator-mediator variable distinction in social psychological research: Conceptual, strategic, and statistical considerations. J. Pers. Soc. Psychol. 1986, 51, 1173-1182. [CrossRef]

18. Cadenas-Sánchez, C.; Mora-González, J.; Migueles, J.H.; Martín-Matillas, M.; Gómez-Vida, J.; Escolano-Margarit, M.V.; Maldonado, J.; Enriquez, G.M.; Pastor-Villaescusa, B.; de Teresa, C.; et al. An exercise-based randomized controlled trial on brain, cognition, physical health and mental health in overweight/obese children (ActiveBrains project): Rationale, design and methods. Contemp. Clin. Trials 2016, 47, 315-324. [CrossRef]

19. Cole, T.J.; Lobstein, T. Extended international (IOTF) body mass index cut-offs for thinness, overweight and obesity. Pediatr. Obes. 2012, 7, 284-294. [CrossRef]

20. Moore, S.A.; McKay, H.A.; Macdonald, H.; Nettlefold, L.; Baxter-Jones, A.D.G.; Cameron, N.; Brasher, P.M.A. Enhancing a somatic maturity prediction model. Med. Sci. Sports Exerc. 2015, 47, 1755-1764. [CrossRef]

21. Ruiz, J.R.; Castro-piñero, J.; España-romero, V.; Artero, E.G.; Ortega, F.B.; Cuenca, M.M.; Jimenez-pavón, D.; Chillón, P.; Girela-rejón, M.J.; Mora, J.; et al. Field-based fitness assessment in young people: The ALPHA health-related fi tness test battery for children and adolescents. Br. J. Sports Med. 2011, 45, 518-524. [CrossRef] [PubMed]

22. Crabtree, N.J.; Arabi, A.; Bachrach, L.K.; Fewtrell, M.; El-Hajj Fuleihan, G.; Kecskemethy, H.H.; Jaworski, M.; Gordon, C.M. Dual-energy x-ray absorptiometry interpretation and reporting in children and adolescents: The revised 2013 ISCD pediatric official positions. J. Clin. Densitom. 2014, 17, 225-242. [CrossRef] [PubMed] 
23. Ubago-Guisado, E.; Vlachopoulos, D.; Fatouros, I.G.; Deli, C.K.; Leontsini, D.; Moreno, L.A.; Courteix, D.; Gracia-Marco, L. Longitudinal determinants of 12-month changes on bone health in adolescent male athletes. Arch. Osteoporos. 2018, 13, 106. [CrossRef] [PubMed]

24. Vlachopoulos, D.; Ubago-Guisado, E.; Barker, A.R.; Metcalf, B.S.; Fatouros, I.G.; Avloniti, A.; Knapp, K.M.; Moreno, L.A.; Williams, C.A.; Gracia-Marco, L. Determinants of Bone Outcomes in Adolescent Athletes at Baseline: The PRO-BONE Study. Med. Sci. Sports Exerc. 2017, 49, 1389-1396. [CrossRef] [PubMed]

25. Hayes, A.F. Beyond Baron and Kenny: Statistical Mediation Analysis in the New Millennium. Commun. Monogr. 2009, 76, 408-420. [CrossRef]

26. Munns, C.F.; Shaw, N.; Kiely, M.; Specker, B.L.; Thacher, T.D.; Ozono, K.; Michigami, T.; Tiosano, D.; Mughal, M.Z.; Mäkitie, O.; et al. Global Consensus Recommendations on Prevention and Management of Nutritional Rickets. J. Clin. Endocrinol. Metab. 2016, 101, 394-415. [CrossRef]

27. Hauksson, H.H.; Hrafnkelsson, H.; Magnusson, K.T.; Johannsson, E.; Sigurdsson, E.L. Vitamin D status of Icelandic children and its influence on bone accrual. J. Bone Miner. Metab. 2016, 34, 580-586. [CrossRef]

28. Zhu, K.; Oddy, W.H.; Holt, P.; Ping-Delfos, W.C.S.; Mountain, J.; Lye, S.; Pennell, C.; Hart, P.H.; Walsh, J.P. Tracking of Vitamin D status from childhood to early adulthood and its association with peak bone mass. Am. J. Clin. Nutr. 2017, 106, 276-283. [CrossRef]

29. Stein, E.M.; Laing, E.M.; Hall, D.B.; Hausman, D.B.; Kimlin, M.G.; Johnson, M.A.; Modlesky, C.M.; Wilson, A.R.; Lewis, R.D. Serum 25-hydroxyvitamin D concentrations in girls aged 4-8 y living in the southeastern United States. Am. J. Clin. Nutr. 2006, 83, 75-81. [CrossRef]

30. Zhai, L.; Liu, J.; Zhao, J.; Liu, J.; Bai, Y.; Jia, L.; Yao, X. Association of obesity with onset of puberty and sex hormones in Chinese girls: A 4-year longitudinal study. PLoS ONE 2015, 10, e0134656. [CrossRef]

31. Zhai, L.; Zhao, J.; Bai, Y.; Liu, L.; Zheng, L.; Jia, L.; Yao, X. Sexual development in prepubertal obese boys: A 4-year longitudinal study. J. Pediatr. Endocrinol. Metab. 2013, 26, 895-901. [CrossRef] [PubMed]

32. Foo, L.H.; Zhang, Q.; Zhu, K.; Ma, G.; Hu, X.; Greenfield, H.; Fraser, D.R. Low Vitamin D Status Has an Adverse Influence on Bone Mass, Bone Turnover, and Muscle Strength in Chinese Adolescent Girls. J. Nutr. 2009, 139, 1002-1007. [CrossRef] [PubMed]

33. Ward, K.A.; Das, G.; Berry, J.L.; Roberts, S.A.; Rawer, R.; Adams, J.E.; Mughal, Z. Vitamin D status and muscle function in post-menarchal adolescent girls. J. Clin. Endocrinol. Metab. 2009, 94, 559-563. [CrossRef] [PubMed]

34. Blakeley, C.E.; Van Rompay, M.I.; Schultz, N.S.; Sacheck, J.M. Relationship between muscle strength and dyslipidemia, serum $25(\mathrm{OH}) \mathrm{D}$, and weight status among diverse schoolchildren: A cross-sectional analysis. BMC Pediatr. 2018, 18, 1-9. [CrossRef] [PubMed]

35. Frost, H.M. Bone's Mechanostat: A 2003 Update. Anat. Rec.—Part A Discov. Mol. Cell. Evol. Biol. 2003, 275, 1081-1101. [CrossRef]

36. Ceglia, L. Vitamin D and Its Role in Skeletal Muscle. Curr. Opin. Clin. Nutr. Metab. Care 2009, 12, $628-633$. [CrossRef]

37. Cossio-Bolaños, M.; Lee-Andruske, C.; de Arruda, M.; Luarte-Rocha, C.; Almonacid-Fierro, A.; Gómez-Campos, R. Hand grip strength and maximum peak expiratory flow: Determinants of bone mineral density of adolescent students. BMC Pediatr. 2018, 18, 96. [CrossRef]

38. Foley, S.; Quinn, S.; Dwyer, T.; Venn, A.; Jones, G. Measures of childhood fitness and body mass index are associated with bone mass in adulthood: A 20-year prospective study. J. Bone Miner. Res. 2008, 23, 994-1001. [CrossRef]

(C) 2019 by the authors. Licensee MDPI, Basel, Switzerland. This article is an open access article distributed under the terms and conditions of the Creative Commons Attribution (CC BY) license (http://creativecommons.org/licenses/by/4.0/). 